\title{
DESCRIPCIÓN CURATORIAL Y AUDIODESCRIPCIÓN DE LAS OBRAS DE ARTE. UN ESTUDIO COMPARATIVO ${ }^{1}$
}

\author{
Anna Wendorff \\ Aneta Pawlowska \\ Universidad de Łódź
}

Data recepción: 2019-12-11

Data aceptación: 2020-02-01

Contacto autoras: anna.wendorff@uni.lodz.pl; aneta.pawlowska@uni.lodz.pl

ORCID: https://orcid.org/0000-0003-0829-6603

ORCID: https://orcid.org/0000-0003-2847-4403

\section{RESUMEN}

El artículo reflexiona sobre la traducción de la imagen en palabras. En la primera parte se enumeran las teorías que relacionan la imagen con la palabra, a continuación se acerca el tema de las audiodescripciones (descripciones verbales para las personas con deficiencia visual) de las obras de arte. En la parte práctica se compara la descripción curatorial y la audiodescripción de la Sala Neoplástica del Museo de Arte de Łódź para analizar cómo la situación de la recepción de la obra audiodescrita modifica la forma de su descripción. Asimismo se indican los cambios actuales en la percepción y escritura de las audiodescripciones de las obras de arte. Igualmente se toca el problema de la elección de la técnica adecuada, desde el punto de vista de los métodos contemporáneos del análisis de las bellas artes para la creación de las audiodescripciones.

Palabras clave: audiodescripción, descripción curatorial, arte, hermenéutica de la imagen, personas con deficiencia visual

\section{ABSTRACT}

The article ponders the translation of an image into words. It begins by discussing theories combining the image with the word before assessing the issue of audio descriptions (verbal descriptions for people with visual impairments) of works of art. The practical part of the article presents a comparative study of curatorial description and audio description from the Neoplastic Room at the Museum of Art in Łódź, which analyses how the way in which the audio description of a piece is received influences the manner in which it is described. The article also describes ongoing changes in the perception and writing of the audio descriptions of artworks and addresses the problem of choosing a suitable technique for creating audio description from the standpoint of contemporary methods of analysing fine art.

Keywords: audio description, curatorial description, art, image hermeneutics, people with visual impairment 


\section{Imagen y palabra. Pequeño esbozo teó-} rico

Desde el punto de vista de la historia del arte, la descripción discursiva de una obra de arte es el inicio de un debate y un diálogo entre el crítico o teórico de arte que explica la obra y su destinatario. En contraposición a una simple descripción de inventario, este relato verbal es el único medio disponible para el análisis del "lenguaje" visual, por lo que el problema de traducir una imagen en palabras y la relación entre "lo expresado" y "lo visible" está constantemente presente en la reflexión metodológica sobre la práctica de una disciplina artística. La naturaleza fundamental de la reflexión "lingüística" sobre el arte la convierte en un punto de partida para el debate sobre la percepción del arte en las últimas décadas. Según la hermenéutica de la imagen, propuesta por Gottfried Boehm en la introducción a su texto programático: "[la hermenéutica] proviene de una fuente donde la experiencia visual de la imagen pasa al medio del lenguaje" (Boehm 2014,16). Otros filósofos hermenéuticos y estéticos del siglo XX son Martin Heidegger, HansGeorg Gadamer y Paul Ricoeur. Estos emplean el llamado círculo hermenéutico, una figura que describe la forma de entender e interpretar el texto y la imagen. Según esta figura, no se puede entender el todo sin entender el detalle, y el detalle no se puede comprender sin aludir al todo. Así, una interpretación eficaz de la obra consiste en un movimiento circular - del todo al detalle y del detalle al todo (Sochoń 1995, 226). Por otra parte, está la posición representada por Max Imdahl, el creador del concepto de la "icónica"2 desarrollado en los años 70 y basado en la creencia de que la imagen no se constituye a través de la palabra. Según Imdahl, la especificidad del lenguaje visual reside en la visualización de verdades imposibles de expresar en el medio lineal del lenguaje natural. La imagen difiere indudablemente del texto y nunca es el equivalente exacto, porque "la imagen es el resultado de la condensación de significados que, en relación a cada información lingüística, representan la calidad de un nuevo tipo" (Imdahl 2009, 121). Sin embargo, la historia del arte debe esforzarse por acercar las palabras a las imágenes tanto como sea posible, mientras que la estructura de una obra de arte, que es extremadamente compleja, debe ir acompañada de una reflexión discursiva igualmente compleja.

Otro problema que interesa a los historiadores del arte es la intermediación verbal omnipresente en la cultura contemporánea, "un perpetuo murmullo de comentarios estéticos" (Steiner 1991, 10) y "una locura mandarina del discurso secundario" (Ibid., 11), que puede verse no como un problema teórico o metodológico, sino como una amenaza real a la percepción directa de una obra de arte y a su experiencia; puesto que "infesta el pensamiento y la sensibilidad" (Ibid.), como nos convence George Steiner. Además, las numerosas convenciones lingüísticas entre las que se inscriben las metáforas conllevan también otros peligros, como una excesiva tendencia a la exaltación (a través de un lenguaje metafórico demasiado colorido) en las descripciones de las obras de arte. El lenguaje no es una herramienta pasiva. Aquí podemos recordar la frase frecuentemente citada de Wittgenstein: "Los límites de mi lengua son los límites de mi mundo" (Wittgenstein 1975, 22). Durante mucho tiempo, las investigaciones lingüísticas han asumido que "existe una relación específica entre el sistema lingüístico y la estructura de nuestras percepciones del mundo, y lo que es más: ese lenguaje modela nuestra cosmovisión y nuestra forma de pensar" (Barańczak 1977, 161). La historiadora de arte Maria Poprzęcka, al reflexionar acerca de la pregunta de "cómo hablar de arte", llama la atención sobre el hecho de que:

El lenguaje de la historia del arte no es sólo metafórico, sino que es inevitablemente catacrético.

(...) El lenguaje de la historia del arte nos permite capturar una obra de arte solo a través del uso de formas de lenguaje "impuras". Las obras y el lenguaje no existen independientemente unas de otras, como unidades "visuales" y "verbales" puras y diferentes. Sus relaciones se basan en la reciprocidad, no en la oposición. La naturaleza de su percepción es igualmente borrosa (Poprzęcka 2000, 38).

Cabe señalar que la cuestión de la traducción de una imagen a su equivalente verbal ha sido durante mucho tiempo el centro de atención de los historiadores del arte, ya que sólo a través de la mediación verbal es posible intercambiar puntos de vista sobre una obra de arte. 


\section{Audiodescripción de las obras de arte}

Una ambigüedad que prevalece entre los especialistas en cuanto a cómo se puede y debe hablar de arte y de obras de arte, describiéndolas, profundiza en la dificultad de crear una descripción verbal clara y coherente adaptada a las necesidades de las personas con problemas de visión, es decir, la audiodescripción (AD). Definida como:

Servicio de apoyo a la comunicación que consiste en el conjunto de las técnicas y habilidades aplicadas, con objeto de compensar la carencia de captación de la parte visual contenida en cualquier tipo de mensaje, suministrando una adecuada información sonora que la traduce o explica, de manera que el posible receptor discapacitado visual perciba dicho mensaje como un todo harmónico y de la forma más parecida a como lo percibe la persona que ve (Asociación Española de Normalización y Certificación 2005, 4).

Un elemento importante del método de interpretación en la historia del arte, la semiótica de la imagen -esto es, el significado de la relación entre el signo (imaginación en la imagen) y la realidad- y la interpretación estructuralista de la imagen, así como la tradición del pensamiento europeo en general, es la atribución a la imagen de un papel secundario y, por tanto, la convicción de que la relación hermenéutica fundamental entre la palabra y el lenguaje necesita ser reconstruida adecuadamente. Esto es tanto más importante cuanto que algunos artífices de las audiodescripciones son partidarios de abstenerse de hacer comentarios y dar explicaciones, como por ejemplo Barbara Szymańska y Tomasz Strzymiński, de la Fundación Audiodescripción (Fundacja Audiodeskrypcja), autores de los primeros estándares de creación de AD para producciones audiovisuales. Según estos, los principios básicos de la audiodescripción son: "1. Describe lo que se puede ver en la imagen. No interprete ni presente sus conclusiones, opiniones o motivos mientras describe" (Szymańska and Strzymiński 2010, 22). Así, lo que para algunos audiodescriptores ya constituye una descripción completa, para un historiador del arte significa solo el comienzo de la interacción entre el receptor de la obra de arte y la obra misma, es decir, la separación de la percepción conceptual ${ }^{3}$ de la visión realizada, que se aferra menos a la situación del sujeto, y libera asociaciones visuales sueltas relacionadas con la representación contenida en la imagen. El ya mencionado Imdahl plasma esta distinción en la fórmula conceptual de "reconocer y ver la visión" (Bryl 1993, 68). Según este enfoque, "ver la visión" se aleja del lenguaje, porque es algo que se realiza solo en el acto de mirar. Al mismo tiempo, es la forma de la visión que les falta a las personas con discapacidad visual. Este tipo de visión no declara ni interpreta, sino que implica al espectador en un determinado proceso, basado no en la percepción de lo visible, sino ante todo en "la emergencia de lo visible, dentro de los límites del margen de maniobra que tiene el artista. Una imagen se convierte en un mundo para el ojo que se extiende más allá de los espacios conocidos de forma empírica" (Boehm 2014, 125).

\section{Descripción curatorial versus audiodes- cripción en el ejemplo de La Sala Neoplástica del Museo de Arte de tódź}

En esta parte, las observaciones teóricas se ilustrarán con dos descripciones de la Sala Neoplástica del Museo de Arte de Łódź (Muzeum Sztuki w Łodzi), Polonia: una descripción de una historiadora del arte, Janina Ładnowska, que se creó a finales de la década de 1980 como una descripción curatorial; y una audiodescripción que se creó como resultado de una investigación realizada en el Departamento de Historia del Arte de la Universidad de Łódź en el año académico 2013-2014 para las personas ciegas y con visión parcial.

En primer lugar, la Sala Neoplástica es una obra de arte integral, una síntesis plástica del arte, según el "manifiesto" de De Stijl (Doesburg and Eesteren 1923, 91-92). Es por ello que su descripción, que utiliza principalmente relaciones espaciales y relaciones geométricas, es un buen ejemplo de cómo la experiencia visual de una imagen pasa al medio del lenguaje. En el apéndice presentamos una audiodescripción completa de la Sala Neoplásica (Apéndice 1), y luego la comparamos con fragmentos (debido al tamaño del discurso, en comparación con la AD tres veces más larga) de la descripción de Ładnowska, que se publicó por primera vez en 1991 (Ładnowska 1991, 71-81). 
La descripción de la sala fue elaborada por estudiantes de Historia del Arte de la Universidad de Łódź durante un curso universitario relacionado con el arte del siglo XX, y fue realizada en el semestre de verano del año académico 20132014 por la Prof. Aneta Pawłowska. Las clases se impartieron in situ, es decir, en el Museo de Arte de Łódź (ms $\left.{ }^{1}\right)$. Los ocho estudiantes del curso participaron en talleres especializados preparados para ellos por los empleados del Museo Nacional de Varsovia (Muzeum Narodowe w Warszawie), el Museo de Arte de Łódź, y la Galería Zachęta de Varsovia (Zachęta - Narodowa Galeria Sztuki). También se organizaron consultas adicionales con metodólogos de la Universidad de Łódź (por ejemplo, de la Facultad de Filología). El objetivo del proyecto era que los estudiantes crearan descripciones de exhibiciones particularmente valiosas del Museo de Arte de Łódź en base a las encuestas realizadas previamente en la Asociación Polaca de Invidentes del Distrito de Łódź (Polski Związek Niewidomych Okręg Łódzki), acerca de la percepción de las artes visuales por los ciegos. Además, las frecuentes visitas al museo incrementaron el conocimiento práctico de los estudiantes sobre las tareas del museo de arte contemporáneo. Por iniciativa propia, los estudiantes consultaron electrónicamente las descripciones realizadas con Barbara Szymańska, de la Fundación Audiodescripción (Fundacja Audiodeskrypcja). A la presentación de las descripciones asistieron expertos, personas ciegas, consultores de otros proyectos, p. ej. "Susurros" (Podszepty) del Museo del Palacio de Herbst (Muzeum Pałac Herbsta) en Łódź, así como Robert Więckowski, de la Fundación Cultura sin Barreras (Fundacja Kultury bez Barier). Cabe destacar que, a pesar de la continua discusión entre los centros de audiodescriptores de Białystok (Fundación Audiodescripción, "escuela bialostocka", enfoque objetivo) y Varsovia (Fundación Cultura sin Barreras, "escuela varsoviana", enfoque subjetivo), tanto las personas ciegas como los representantes de las fundaciones, Robert Więckowski y Barbara Szymańska, se mostraron satisfechos con las descripciones realizadas por los estudiantes. La presentación de las descripciones tomó la forma de lecturas en voz alta en el espacio del museo. Los vivos comentarios de los evaluadores del proyecto despertaron relaciones espaciales expresadas en pasos, que no resultaron ser lo suficientemente precisas; igualmente las observaciones se dirigieron hacia el tono de voz y el ritmo de dicción de los estudiantes, ya que leían las descripciones a un ritmo demasiado rápido. La descripción no se grabó, por lo que no adquirió la llamada "etiqueta verbal de objeto presentado" (Szymańska $2015,14)$, que incluiría las dimensiones de la sala en metros. Cabe destacar que ninguno de los alumnos había trabajado antes en las audiodescripciones, y que el curso académico de 30 horas, complementado con consultas con personas con discapacidad visual, era la única fuente de su conocimiento.

Veamos, por tanto, las similitudes y diferencias entre las dos descripciones, la audiodescripción y la descripción del museo, para analizar cómo la situación de la recepción de una obra audiodescrita cambia la forma en que se la describe. 
Tabla 1: Audiodescripción y extractos de la descripción curatorial de la Sala Neoplástica

\begin{tabular}{|c|c|}
\hline $\begin{array}{l}\text { AD de la Sala Neoplástica (Pawłowska and Sowińska-Heim } \\
2016,62-63 \text { ) }\end{array}$ & $\begin{array}{l}\text { Descripción del curador de la Sala Neoplástica (Ładnowska } \\
2015,332-336 \text { ) }\end{array}$ \\
\hline $\begin{array}{l}\text { Nota histórica: } \\
\text { La Sala Neoplásica es un espacio expositivo de vanguardia } \\
\text { diseñado por Władysław Strzemiński para obras recogidas } \\
\text { en la década de 1930, que co-creó la Colección Internacional } \\
\text { de Arte Moderno del grupo "a.r.". La sala fue inaugurada en } \\
\text { 1948, y posteriormente en 1960, cuando fue reconstruida } \\
\text { después de su desmantelamiento durante la época del rea- } \\
\text { lismo socialista (Pawłowska and Sowińska-Heim 2016, 62). }\end{array}$ & $\begin{array}{l}\text { En 1945, Władysław Strzemiński donó al Museo de Arte todas } \\
\text { sus obras más importantes, desde sus primeras composiciones } \\
\text { post-suprematistas, pasando por composiciones unistas, com- } \\
\text { posiciones arquitectónicas, paisajes marítimos y de Łódź, hasta } \\
\text { sus ciclos de dibujo en tiempos de guerra (las obras posteriores } \\
\text { fueron transferidas a medida que se fueron creando). Katarzyna } \\
\text { Kobro también donó sus composiciones espaciales de metal, que } \\
\text { sufrieron graves daños durante la guerra. Fueron preservadas bajo } \\
\text { su dirección por Bolesław Utkin. En 1946, el Museo traslada sus } \\
\text { colecciones al antiguo palacio de Maurycy Poznański (arquitecto } \\
\text { Adolf Seligson, 1896). En la segunda planta del palacio, el di- } \\
\text { rector del Museo Marian Mnich diseña una exposición de arte } \\
\text { moderno polaco e internacional con una disposición sistemática } \\
\text { y estilística. (...) El punto focal era la Sala Neoplástica diseñada } \\
\text { por Władysław Strzymiński en 1948 por orden del director Marian } \\
\text { Mnich. Strzymiński contó con la asistencia de Bolesław Utkin, y el } \\
\text { proyecto fue implementado por Władysław Górski (un artesano, } \\
\text { estudiante de preguerra de Strzemiński en la Escuela Vocacional } \\
\text { Suplementaria No. 10) (Ładnowska } 2015,332 \text { ). } \\
\text { Inaugurada cuatro años antes de la muerte del autor, la Sala } \\
\text { Neoplástica recapitulaba las ideas de la nueva arquitectura, que } \\
\text { aún no se habían materializado en la práctica. (...) En la década de } \\
\text { 1940, Strzemiński no había pintado desde hacía mucho tiempo } \\
\text { ni composiciones arquitectónicas ni unísticas, mientras que "la } \\
\text { integridad de la pintura abstracta" lo llevó a la enseñanza en la } \\
\text { Escuela Superior de Artes Plásticas (siglas polacas PWSSP) en Łódź } \\
\text { (Ładnowska 2015, 336). }\end{array}$ \\
\hline $\begin{array}{l}\text { La sala tiene una planta rectangular con el ala izquierda alar- } \\
\text { gada (Pawłowska and Sowińska-Heim 2016, 62). }\end{array}$ & $\begin{array}{l}\text { La sala (...) está situada en una planta rectangular, 5,28 m x9,60 mx } \\
4,20 \text { m (altura). Los muros más largos están situados al oeste y } \\
\text { al este, los más cortos al norte y al sur (Ładnowska 2015, 332). }\end{array}$ \\
\hline $\begin{array}{l}\text { En las paredes y el techo, hay pintados rectángulos de varios } \\
\text { tamaños en colores básicos (rojo, amarillo, azul) y neutros } \\
\text { (blanco y negro) (Pawłowska and Sowińska-Heim 2016, 62). }\end{array}$ & $\begin{array}{l}\text { Las paredes y el techo están divididos en planos utilizando colo- } \\
\text { res básicos- rojo, azul, amarillo - y neutros - blanco y negro (...) } \\
\text { (Ładnowska 2015, 332). }\end{array}$ \\
\hline $\begin{array}{l}\text { Delante de ti, se halla la esquina izquierda de la habitación, } \\
\text { que al final está truncada. Hay una gran ventana rectangular } \\
\text { con dieciséis cristales y un amplio alféizar (Pawłowska and } \\
\text { Sowińska-Heim 2016, 62). }\end{array}$ & $\begin{array}{l}\text { La ventana situada en una pared diagonal está representada por } \\
\text { los colores rojo, negro, blanco y amarillo, encima de la ventana } \\
\text { - plano gris (Ładnowska 2015, 333). }\end{array}$ \\
\hline $\begin{array}{l}\text { A la derecha de la ventana hay una parte redondeada y } \\
\text { convexa de la pared (...) (Pawłowska and Sowińska-Heim } \\
2016,62 \text { ). }\end{array}$ & La pared sur está redondeada (Ładnowska 2015, 332). \\
\hline $\begin{array}{l}\text { En el centro del techo, hay una claraboya dividida en doce } \\
\text { cuadrados (Pawłowska and Sowińska-Heim 2016, 62). }\end{array}$ & En el centro del techo hay una claraboya (Ładnowska 2015, 332). \\
\hline $\begin{array}{l}\text { Frente a ellas, cuatro esculturas de Katarzyna Kobro están } \\
\text { colocadas sobre paralelepípedos de vidrio (Pawłowska and } \\
\text { Sowińska-Heim 2016, 63). }\end{array}$ & $\begin{array}{l}\text { Los pedestales de esculturas de vidrio están a la misma altura que } \\
\text { una franja negra, horizontal, inferior, que subraya los colores y la } \\
\text { espacialidad de la composición (Ładnowska 2015, 333). }\end{array}$ \\
\hline $\begin{array}{l}\text { En la pared de la derecha hay siete pinturas colgadas a una } \\
\text { distancia de medio metro. (...) A la derecha, la primera, Con- } \\
\text { tracomposición XV de Theo von Doesburg. Al lado la Com- } \\
\text { posición de Sophie Taeuber-Arp. Frente a ellas se encuentra } \\
\text { la escultura Composición Espacial (3). Sigue } 2 \text { pasos, a la } \\
\text { derecha se encuentra la pintura Composición de Taeuber- } \\
\text { Arp. Frente a ella la escultura de Kobro Composición espacial } \\
\text { (2) (Pawłowska and Sowińska-Heim 2016, 63). }\end{array}$ & $\begin{array}{l}\text { Los autores de las pinturas expuestas en la Sala Neoplástica son } \\
\text { artistas directamente relacionados con el grupo y la revista De } \\
\text { Stijl, además de pertenecer a un círculo bastante amplio de sim- } \\
\text { patizantes. Los rasgos comunes de las pinturas son las formas } \\
\text { geométricas abstractas, el uso de colores básicos y neutros (...), } \\
\text { la ortodoxia de lo vertical y lo horizontal se difumina por la diná- } \\
\text { mica de las líneas diagonales de van Doesburg, círculos y líneas } \\
\text { diagonales en las composiciones de Sophie Taeuber-Arp, rombos } \\
\text { en Composición - figura humana de Huszár, arcos en Henryk } \\
\text { Stażewski. A pesar de estas características colaterales, las imáge- } \\
\text { nes forman un todo unificado. Los coloridos planos de imágenes } \\
\text { se "transfieren" a las coloridas superficies de paredes y esculturas, } \\
\text { y el espectador que está en el medio de este espacio participa } \\
\text { en la creación de un "Gesamtkunstwerk" específico que genera } \\
\text { tensiones enérgicas (Ładnowska 2015, 334). }\end{array}$ \\
\hline
\end{tabular}


En cuanto a la información histórica, en el caso de la $A D$ aparece al principio de la descripción, separándose de la descripción detallada, que es concisa y simple, usa la voz pasiva y las frases impersonales. Sin embargo, la descripción museográfica es muy detallada (abarca desde el origen de la formación de la colección museográfica), utiliza terminología especializada del periodo de la historia del arte pertinente, por ejemplo las tendencias de la pintura abstracta (postsuprematismo, unismo, etc.), predominando aquí las formas personales y la voz activa. Tiene una construcción de cierre, ya que aparece al principio y al final de la descripción.

En la AD detallada sólo se hacía una aproximación de la forma de la sala ("una planta rectangular con el ala izquierda alargada"), dado que el resto de los datos se encontraban en la "etiqueta verbal", mientras que en la descripción de Ładnowska, a parte de la forma, se daban también las medidas exactas de la longitud, la altura y el ancho. Estas diferencias se deben, sin lugar a dudas, a las directrices de ahorro de palabras en las audiodescripciones.

La superficie cromática en ambas descripciones posee una característica bastante similar, ya que se trabaja con colores básicos y neutros, representativos de neoplasticismo. Observamos la diferencia en la estructura de las frases, simplificadas en el caso de la audiodescripción: "En las paredes y el techo, hay pintados rectángulos de varios tamaños en colores...", frente a "Las paredes y el techo están divididos en planos utilizando colores...".

En la $A D$ se describe la posición de la ventana con ayuda de una esquina truncada de la sala, en la de Ładnowska aparece una pared diagonal, un concepto difícil de comprender, especialmente para una persona ciega de nacimiento, para la que una "esquina truncada" es algo más tangible y fácil de imaginar, según dicen las encuestas. La audiodescripción se centra en una posición más precisa de la ventana, así como su forma y aspecto ("gran ventana rectangular con dieciséis cristales y un amplio alféizar"), ya que los audiodescriptores se dieron cuenta de que esta aclaración hace más fácil la visita de los receptores con deficiencias visuales, dirigiendo la atención de las personas con baja visión ${ }^{4}$ hacia la poten- cial fuente de luz y facilitándoles que imaginen los reflejos de los rayos del sol en la estancia. La descripción de Ładnowska se refiere sobre todo a los elementos plásticos, los colores ("La ventana [...] está representada por los colores rojo, negro, blanco y amarillo, encima de la ventana - plano gris"), que son una pieza clave para concebir a Władysław Strzemiński.

En la siguiente descripción audiodescriptiva el efecto de la pared redondeada se ve reforzado por su convexidad ("una parte redondeada y convexa de la pared" versus "La pared sur está redondeada"). Como sabemos las personas ciegas conocen el mundo en mayor medida a través del tacto y los artistas se esfuerzan en acercarles su arte por este medio. Cabe mencionar el proyecto en blanco y negro "Tocando la fotografía" (Dotykając fotografii) del año 2017 de Rafał Kuszpyt, en el que el autor se dio a la tarea de convertir su obra fotográfica en un bajorrelieve. Hizo convexos los negros y cóncavos los blancos en diferente medida según las tonalidades, de forma que una persona con disfunción visual pudiera "sentir" los claroscuros.

La construcción de vidrio es aproximada en ambas descripciones", en la AD sólo se ha detallado el aspecto usando figuras geométricas ("doce cuadrados"); de forma similar a la siguiente descripción, en la que se describe los pedestales como "paralelepípedos". Aquí de nuevo observamos que Ładnowska pone el acento sobre todo en los colores de la composición ("una franja negra", "subraya los colores"), mientras que la audiodescripción se centra en la forma. El énfasis en los colores básicos y neutros que hace un historiador del arte profesional es el resultado del amplio conocimiento de los colores precedentes para la teoría del neoplasticismo, algo que según han reconocido los audiodescriptores, no tendrá mayor importancia para los receptores que tienen menos conocimientos de historia del arte.

Si hablamos de los cuadros en la AD de la Sala Neoplástica, estos solo se mencionan. Cabe destacar que el proyecto audiodescriptivo de la Cátedra de Historia del Arte de la Universidad de Łódź, a excepción de la descripción general de la Sala Neoplástica, abarcaba también cuatro obras de dicha sala, que fueron descritas de forma individual detalladamente, Contracomposición XV de 
Doesburg, Composición unista 11 de Strzemiński, Composición de tres equivalentes de Vantongerloo y Cuadro abstracto /I de Stażewski. Vemos también que en la audiodescripción los cuadros han sido "intercalados" con las esculturas, lo que se debe a que la descripción se hace por orden de la visualización de estas ("a la derecha", "al lado", "delante de ti") y está ligada a las así llamadas audiodescripciones guiadas, que se usan para moverse por el museo (ej. "da dos pasos", "sigue 2 pasos")6. Además esto se puede aplicar también al orden en que se describe toda la Sala Neoplástica, por ejemplo, la pared diagonal se describe antes de la pared redondeada, al contrario de lo que sucede en la descripción de Ładnowska. También se describe la relación espacial de los cuadros ("una distancia de medio metro"), de modo que la persona con discapacidad visual pueda imaginarse su colocación. Destaquemos que desde el punto de vista de un historiador de arte o de un traductor es curiosa la forma en que se construyen frases sencillas, sin doble sentido, donde la narración de la descripción es lineal, de modo que el invidente se pueda orientar sobre el aspecto de cierto objeto, cuadro, espacio o forma arquitectónica.

Sin embargo, el curador "entrelaza" la descripción de los cuadros con el contexto cultural ("artistas directamente relacionados con el grupo y la revista 'De Stijl'"); recordemos que en la audiodescripción este únicamente se menciona en la primera parte: la nota histórica. Ładnowska utiliza un lenguaje más bien especializado ("Gesamtkunstwerk") y metafórico ("se difumina por la dinámica de las líneas diagonales...", "Los coloridos planos de imágenes se 'transfieren' a las coloridas superficies de paredes y esculturas"), hace referencia a todos los cuadros al mismo tiempo, señala los elementos que los unen ("Los rasgos comunes de las pinturas son..."), interpretándolos de esta manera y aclarando el espacio descrito. En la audiodescripción tenemos un lenguaje seco, preciso, matemático ("siete pinturas", "medio metro"), los pasos contados y "medidos", libre de cualquier interpretación. La filosofía más cercana al origen de esta audiodescripción sería por lo tanto la llamada "escuela bialostocka", aunque así como hemos dicho antes, tanto la Fundación Audiodescripción como la Fundación Cultura sin Barreras estuvieron in- volucradas en su proceso de creación y ambas la aceptaron. Preguntémonos también si existiría la posibilidad de aprovechar la descripción de Ładnowska, o en un contexto más amplio la descripción del curador en general, para crear una audiodescripción. Sin lugar a dudas, serviría como punto de partida para futuros trabajos, ya que podríamos utilizar solo algunos fragmentos que deberían ser adaptados a las necesidades de las personas con discapacidad visual. Aún más cercana a la audiodescripción es la descripción conocida como tarjeta de catálogo o de inventario del objeto, la cual podría desempeñar el papel de una AD objetiva, una vez adaptado el texto a la percepción de las personas con discapacidad visual, agregando información sobre las relaciones espaciales, entre otras cosas.

\section{Audiodescripción de las obras de arte. Nuevos enfoques}

En los últimos años observamos cambios en la forma de audiodescribir las obras de arte. Cada vez más el audiodescriptor se aleja de una audiodescripción objetiva para mostrar las emociones y sentimientos de tal forma que el receptor minusválido sienta el placer estético. En tal sentido la audiodescripción se está acercando a la descripción curatorial en dos aspectos: usa conscientemente los tropos literarios y proporciona más información explicativa del contexto de la historia de arte.

Las encuestas del año 2013 tituladas "El arte que (no) se puede ver" (Sztuka [nie] do zobaczenia), en las que participaron 210 personas invidentes y con baja visión (Figiel and Więckowski 2014, 73-83), señalaron que para el $31 \%$ de los encuestados la finalidad primordial de una visita al museo es la experiencia estética, la estimulación de la imaginación y las emociones relacionadas con el contacto con los artefactos; mientras que para el $30 \%$ de los encuestados la clave era el correcto conocimiento de las obras de arte. Aparte de esto, la mayoría de las personas con incapacidad visual $(75,8 \%)$ declara que conocería la obra de arte, si además del aspecto de la pieza, se describiese también sus componentes más importantes y el contexto de su origen, lo que señala expresamente la necesidad de colocar 
las audiodescripciones dentro del discurso de la historia del arte.

Desde el año 2013 se han realizado sucesivos estudios en la universidad de Łódź que muestran que los estudiantes de historia de arte que se apoyan en el conocimiento adquirido durante sus estudios y la formación sobre creación de AD son capaces de elaborar audiodescripciones completamente satisfactorias para una persona con discapacidad visual, uniendo de forma natural en sus descripciones los elementos de historia de las teorías artísticas. Estas descripciones, de manera más o menos consciente, utilizan un método hermenéutico para analizar la obra de arte tal y como lo concebía Hans-Georg Gadamer, tomando en cuenta que el sujeto (en nuestro caso el audiodescriptor) no puede interpretar el texto ni el cuadro partiendo de una posición neutral de cero, carente de cualquier expectativa, y que la experiencia estética (que es la esencia del contacto con la obra de arte) está ligada al juego libre del intelecto y la imaginación (Gadamer 1979, 148), uniendo la capacidad de crear cuadros con la capacidad de entender. Sobre todo, la interpretación de Gadamer destaca el significado de la dimensión simbólica y la alusión en las obras de arte. Por eso parece imposible y tal vez infundada la idea de eliminar de la AD las expresiones subjetivas o un lenguaje ligeramente más locuaz. Según la opinión de las autoras, tal descripción puede facilitar lo que se conoce como concretización estética de la obra de arte (Ingarden 1966, 141).

Subrayemos también que hay autores, como Izabela Künstler-Zawisza, que empiezan a considerar la AD más en las categorías de la narración que estricta descripción, opinando que detenerse en la superficie de la imagen y "lo que se ve" impide escribir una audiodescripción atractiva, pictórica e interesante (Künstler-Zawisza 2017). Otros, como por ejemplo Agnieszka Szarkowska y Piotr Wasylczyk, partiendo del cine de autor, crean audiodescripción de autor aplicada a ese tipo de películas (Szarkowska and Wasylczyk 2014, 48-62), en la que se trataría de reflejar la visión propia de los creadores del séptimo arte, sobre todo del director-autor (Ibid., 48), a través de tales métodos y técnicas como: la interpretación subjetiva, las alusiones al lenguaje fílmi- co, las expresiones poéticas, las metáforas, las comparaciones, la descripción de las emociones de los protagonistas, los neologismos, el uso del lenguaje coloquial o/y del idiolecto del autor de la película (Ibid., 49). Basándose en la audiodescripción de autor para las películas se creó la audiodescripción de autor para las obras de arte, en las que se trataría de representar la visión del pintor o escultor; etc. Tentativas de este tipo las hizo Beata Jerzakowska en su manual de lengua polaca con la audiodescripción de las 70 reproducciones de obras de arte, titulado Escuchar a los cuadros (Posłuchać obrazów) (Jerzakowska 2016), lo que a continuación describió en su doctorado "Audiodescripción de la pintura - determinantes del género y sus realizaciones textuales" (Audiodeskrypcja malarstwa - wyznaczniki gatunku i ich realizacje tekstowe) (Jerzakowska 2018). Las audiodescripciones de esta autora tienen un carácter subjetivo y emocional, usan diferentes figuras literarias (epítetos, preguntas retóricas, metáforas, etc.) que potencian la carga emocional del texto, beben de la poesía, emplean los elementos ecfrásticos, también se sirven de buen grado del lenguaje de las bellas artes, traducen la simbología de las obras de arte y presentan las interpretaciones o las sugestiones interpretativas de las obras. En las grabaciones de las $A D$, aparte de las palabras, podemos oír también los sonidos y la música en el fondo que armoniza con el texto de la audiodescripción. Estas audiodescripciones procuran en su forma de ser acercarse a las bellas letras, a los textos artísticos. Si se trata del lenguaje, con frecuencia usan el presente histórico y las formas personales para que el receptor se involucre más en la obra (Ibid., 338-379).

Se sigue trabajando asimismo en potenciar la conjunción de la audiodescripción con las sensaciones percibidas por otros sentidos y el uso más avanzado de las nuevas tecnologías siempre con el fin de hacer el arte más accesible y aguzar los sentimientos estéticos de las personas con deficiencia visual.

\section{A modo de conclusión}

Los estudios sobre la audiodescripción son interdisciplinarios por su propia naturaleza. Las autoras, al cotejar las experiencias concernientes a la traducción de la imagen en la palabra (tema 
tan discutido en las teorías estéticas modernas), así como de la relación entre lo visual y lo verbal con la labor de traducción y la experiencia museística, querrían señalar ciertas regularidades en la creación de audiodescripciones de obras de arte.

Reflexionando sobre el problema de la selección de un método adecuado para la creación de una audiodescripción, desde el punto de vista de los métodos contemporáneos de análisis de las obras de arte, debemos más bien quedarnos en el ámbito de la hermenéutica antes que examinar la tarea del audiodescriptor en el contexto del método icónico de Max Imdahl, ya que en este caso cualquier traslación de una imagen a lenguaje verbal estaría de antemano condenada al fracaso. El creador de la AD debería tener en cuenta el hecho de que "El lenguaje (...) del arte no es sólo metafórico, sino que es inevitablemente catacrético" (Poprzęcka 2000, 38); simultáneamente, debería rechazar "una locura mandarina del discurso secundario" (Steiner 1991, 11). 


\section{NOTAS}

1 Las autoras del presente texto ya han trabajado este tema en otro artículo presentado en la revista Przekładaniec que fue escrito en lengua polaca. Para mayor detalle véase: (Pawłowska and Wendorff 2017, 86-106).

2 Icónica: método de investigación que Imdahl desarrolló en los años 70. Se inscribe dentro de la corriente de la hermenéutica, sin embargo, la icónica significa una mejor comprensión de una obra de arte. Llama la atención sobre la combinación de forma y contenido, ya que una obra de arte es un fenómeno visual. La icónica ve las relaciones formales, como por ejemplo la tensión direccional y las líneas. Proporciona una perspectiva que recurre a la imagen como medio, es decir, muestra lo que es irremplazable en la imagen. Según el icono, la visión física (reconocer) y la visión formal (ver) se complementan entre sí, llevando a la visión de un orden superior, cuyos significados van más allá de la experiencia visual práctica. El icono no busca un valor simbólico.

3 Esta percepción puede estar contenida en el lenguaje y en los conceptos, es decir, descrita.

4 Con base en el Informe sumario sobre el diagnóstico de los servicios prestados en materia de rehabilitación social para personas discapacitadas en Polonia (Zbiorczy raport $z$ diagnozy świadczonych usług z zakresu rehabilitacji społecznej dla osób niepełnosprawnych w Polsce), se concluye que las personas completamente ciegas son solo el $5 \%$ de la población con discapacidad visual, para el resto de los receptores de las AD la información sobre la fuente de luz es importante (Kaczmarek 2011, 5).

5 Los estudiantes no conocían la descripción de Ładnowska durante el ejercicio de la audiodescripción, de ahí que no fuera tomada en cuenta en el momento de su elaboración.

6 La sala es estrecha con un camino de alfombra de fieltro, de ahí que los audiodescriptores pensaron que no había necesidad de describir el movimiento izquierda/derecha, sin embargo, el problema señalado por las personas invidentes era la diferencia del tamaño de los pasos. Para compensar este inconveniente es imprescindible aplicar un sistema de localizadores precisos (p. ej. a través de una red de beacons y una aplicación móvil) o caminos que guíen a los invidentes, algo que en la antigua tela de la Sala Neoplástica es imposible.

\section{APÉNDICE}

\section{La Sala Neoplástica}

Nota histórica: La Sala Neoplástica es un espacio expositivo de vanguardia diseñado por Władysław Strzemiński para obras recogidas en la década de 1930, que co-creó la Colección Internacional de Arte Moderno del grupo "a.r.". La sala fue inaugurada en 1948, y posteriormente en 1960, cuando fue reconstruida después de su desmantelamiento durante la época del realismo socialista. Descripción detallada:

Estás frente a la Gran Sala Neoplástica. Da cinco pasos.

Ahora estás dentro de la habitación.

La sala tiene una planta rectangular con el ala izquierda alargada.

Estás parado sobre una alfombra negra que corre a lo largo de la mitad de la habitación.

En las paredes y el techo, hay pintados rectángulos de varios tamaños en colores básicos (rojo, amarillo, azul) y neutros (blanco y negro).

A la derecha hay un amplio pasillo que conduce a la siguiente exposición.

Gira a la izquierda.

En la pared de la izquierda hay colgados tres cuadros.

Delante de ti, se halla la esquina izquierda de la habitación, que al final está truncada. Hay una gran ventana rectangular con dieciséis cristales y un amplio alféizar.

A la derecha de la ventana hay una parte redondeada y convexa de la pared, y junto a ella hay un pasadizo a la Sala Neoplástica Menor.

En el centro del techo, hay una claraboya dividida en doce cuadrados.

En la pared de la derecha hay siete pinturas colgadas a una distancia de medio metro. Frente a ellas, cuatro esculturas de Katarzyna Kobro están colocadas sobre paralelepípedos de vidrio. Los pedestales tienen una altura de aproxi- madamente 1 metro. A la derecha, la primera, Contracomposición XV de Theo von Doesburg. Al lado la Composición de Sophie Taeuber-Arp. Frente a ellas se encuentra la escultura Composición Espacial (3). Sigue 2 pasos, a la derecha se encuentra la pintura Composición de Taeuber-Arp. Frente a ella la escultura de Kobro Composición espacial (2).

Da 2 pasos más -A la derecha, la Composición de Jean Helion.

Entre ella y la siguiente pintura - la escultura de Kobro, Composición Espacial (4).

En el lado izquierdo, en la pared opuesta, se encuentra el Cuadro Abstracto II de Stażewski.

Dos pasos más allá: a la derecha, Georges Vantongerloo Composición de tres equivalentes.

Entre esta obra y la siguiente pintura, Composición espacial de Kobro (6).

A la izquierda, en la pared opuesta, está la Composición de Stażewski

Dos pasos más adelante: a la derecha, el cuadro de Vilmos Huszár, Composición Figura humana.

A la izquierda, en la pared opuesta, la Composición textual de Stażewski.

Frente a él se encuentra un cuadro de Vilmos Huszár, Composición.

Da dos pasos y gira en el sentido de las agujas del reloj.

Enfrente el último cuadro - Kobro, Composición Abstracta.

Da dos pasos y gira a la izquierda.

Frente a ti, la entrada a la Sala Neoplástica Menor.

Después de 5 pasos estarás dentro del Pequeño Cuarto Neoplástico.

Es rectangular con una esquina inferior izquierda truncada.

A la izquierda hay una ventana.

En el centro del techo una claraboya cuadrada.

A las 11 a.m. el trabajo de Strzemiński.

A la derecha se encuentra la Composición unista 11 de Strzemiński.

A la izquierda, sobre el fondo de la ventana, una escultura de Kobro.

Delante de ti hay un pasaje a la próxima exposición (Pawłowska and SowińskaHeim 2016, 62-63). 


\section{REFERENCIAS}

Asociación Española de Normalización y Certificación. Norma UNE 153020. Audiodescripción para personas con discapacidad visual. Requisitos para la audiodescripción y elaboración de audioguías. Madrid: AENOR, 2005.

Barańczak, Stanisław. "Problematyka funkcji perswazyjnej tekstów literackich i paraliterackich w świetle tez Semantyki Ogólnej." Studia Polonistyczne 4 (1977): 155-165.

Boehm, Gottfried. O obrazach i widzeniu. Antologia tekstów, edited by Daria Kołacka. Translated by Małgorzata Łukasiewicz, Anna Pieczyńska-Sulik. Kraków: Universitas, 2014.

Bryl, Mariusz. "Płaszczyzna, ogląd, absolut. Inspiracje hermeneutyczne we współczesnej historii sztuki." Atrium Quaestiones VI (1993): 55-85.

Doesburg, Theo van, and Cornelis van Eesteren. "Tot een beeldende Architektuur." De Stijl VI, no. 6/7 (1923): 91-92.

Figiel, Wojciech, and Robert Więckowski. "Sztuka (nie) do zobaczenia: badanie preferencji odbiorców audiodeskrypcji do dzieł sztuki za pomocą metod ilościowych." Komunikacja Specjalistyczna. Communication for Special Purposes. Fachsprachen kommunikation. Professionalnaja kommunikacija VIII (2014): 73-83.

Gadamer, Hans-Georg. Rozum, słowo, dzieje. Szkice wybrane, edited by Krzysztof Michalski. Translated by Małgorzata Łukasiewicz, Krzysztof Michalski. Warszawa: PIW, 1979.

Imdahl, Max. "Giotto: z zagadnień ikonicznej struktury sensu." In Perspektywy współczesnej historii sztuki. Antologia przekładów, Artium Quaestiones, edited by Mariusz Bryl, Piotr Juszkiewicz, Piotr Piotrowski, Wojciech Suchocki, 111-138. Poznań: Wydawnictwo Naukowe UAM, 2009.

Ingarden, Roman. Przeżycie, dzieło, wartość. Kraków: Wydawnictwo Literackie, 1966.

Jerzakowska, Beata. "Audiodeskrypcja malarstwa - wyznaczniki gatunku i ich realizacje tekstowe." PhD diss., Adam Mickiewicz University, 2018.
Jerzakowska, Beata. Posłuchać obrazów. Poznań: Wydawnictwo Rys, 2016.

Kaczmarek, Beata M., ed. Zbiorczy raport z diagnozy świadczonych usług z zakresu rehabilitacji społecznej dla osób niepełnosprawnych w Polsce. Warszawa: Fundacja Batorego, 2011.

Künstler-Zawisza, Izabela. Audiodeskrypcja jako narracja. Zastosowanie analizy filmu oraz analizy jego percepcji w pisaniu i nauczaniu audiodeskrypcji. Warszawa, 2017.

Ładnowska, Janina. "Sala Neoplastyczna - z dziejów kolekcji sztuki nowoczesnej w Muzeum Sztuki w Łodzi." In Miejsce sztuki.Museum Theatrum Sapientiae, Theatrum Anima-bile, edited by Zespół kustoszy Muzeum Sztuki w Łodzi, 71-81. Łódź: Muzeum Sztuki, 1991.

Ładnowska, Janina. "Sala Neoplastyczna - z dziejów kolekcji sztuki nowoczesnej w Muzeum Sztuki w Łodzi." In Muzeum Sztuki w Łodzi. Monografia, vol. 1, edited by Aleksandra Jach, Katarzyna Słoboda, Joanna Sokołowska, Magdalena Ziółkowska, 326-342. Łódź: Muzeum Sztuki w Łodzi, 2015.

Pawłowska, Aneta, and Anna Wendorff. "Obraz opis - symulakrum." Przekładaniec 35 (2017): 86-106.

Pawłowska, Aneta, and Julia Sowińska-Heim. Audiodeskrypcja dzieł sztuki. Metody, problemy, przykłady. Łódź: Wydawnictwo Uniwersytetu Łódzkiego, 2016.

Poprzęcka, Maria. Pochwała malarstwa. Studia z historii i teorii sztuki. Gdańsk: Słowo/Obraz Terytoria, 2000.

Sochoń, Jan. "Hermeneutyka - wstępne rozpoznania." Warszawskie Studia Teologiczne VIII (1995): 219-232.

Steiner, George. Presencias reales. Barcelona: Destino, 1991.

Szarkowska, Agnieszka, and Piotr Wasylczyk. "Audiodeskrypcja autorska." Przekładaniec 28 (2014): 48-62.

Szymańska, Barbara. Rekomendacje dotyczqce udostępniania instytucji muzealnych osobom z niepełnosprawnościq wzroku i tworzenia audiodeskrypcji do dzieł plastycznych. Warszawa: 
314 Descripción curatorial y audiodescripción de las obras de arte. Un estudio comparativo

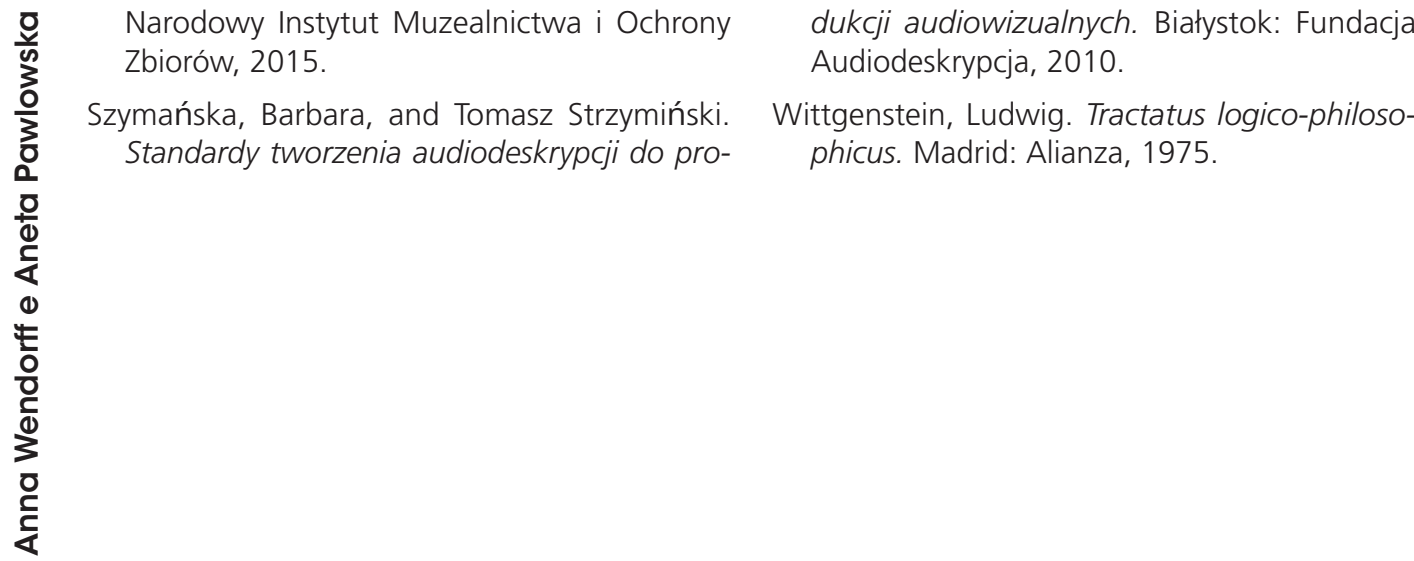

